Original article

\title{
A procedure for identifying chemical and biological risks for books in historic libraries based on microclimate analysis
}

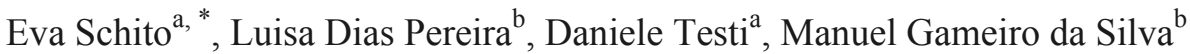 \\ a Department of Energy, Systems, Territory and Constructions Engineering (DESTEC), University of Pisa, Italy \\ b ADAI, LAETA, Department of Mechanical Engineering, Faculty of Sciences and Technology, University of Coimbra, Portugal
}

\section{A R T I C L E IN F O}

\section{Article history:}

Received 12 August 2018

Accepted 9 October 2018

Available online xxx

\section{Keywords}

Microclimate

Risk assessment

Books preservation

Historic buildings and libraries

Preventive conservation

\begin{abstract}
A B S T R A C T
The study presents a new procedure for identifying possible risks for books kept in historic libraries. It is addressed to all those historic libraries where large collections of old and rare books are stored and preserved. These libraries were rarely used by people, but, nowadays, many of them have become touristic attractions. Consequently, their indoor microclimate may have changed, possibly leading to risks for books conservation. The proposed methodology is based on an intensive monitoring campaign, followed by an in-depth data analysis. Handy indices are also proposed to guide the researchers in the identification of possible risks. Problems related to too-high daily or spatial hygrothermal variations or problems related to specific risks (e.g., biological or chemical risks) can be identified. If a problem is observed, the identification of the most suitable solutions is more straightforward. The application of the proposed procedure to a real case study (the Baroque Library of the University of Coimbra, Portugal) has highlighted its handiness. A 6-month monitoring campaign and its consequent data analysis has pointed out potentially risky situations. Thus, measures should be taken to avoid books damage. Primarily, local actions are suggested.
\end{abstract}

\section{Introduction}

The concern with indoor environmental conditions in libraries is relatively recent. The initial studies about the indoor environmental quality in libraries were related particularly to human health problems, trying to associate some parameters (e.g., indoor air temperature and/ or relative humidity, dust, $\mathrm{CO}_{2}$ concentration levels, VOCs, particulate matter) to symptoms and health issues such as the sick buildings syndrome [1-3].

Later on, attention was driven towards the conservation of books. Many researches focus on the relation between microclimate parameters - mostly temperature (T) and relative humidity (RH) - and conservation problems of books [4-6]. In some cases, the issue of books preservation is coupled with multi-objective problems: for example, in [7], the authors study a demand controlled ventilation system to improve energy efficiency in a library, while maintaining suitable microclimate for the library collection conservation.

Among the various types of libraries, in historic libraries, the conservation of books represents a particular challenge. In the European context, many historic libraries are hosted in old and protected buildings, housing rare manuscripts, ancient books and special collections [8-10]. In that sense, these libraries cannot be considered as museums with books, as the books are often stored and available to users only with special permissions, not to hamper their preservation. This

\footnotetext{
Corresponding author.

Email address: eva.schito@for.unipi.it (E. Schito)
}

is the main difference between a museum and a historic library: a museum is a place where artworks are exposed to be visible and appreciated for users, whereas a historic library is a place where books are stored to be preserved. It is also true that many of these libraries are touristic attractions, mainly for their architecture features or historic importance, but, as these buildings often store unique copies of old books, their preservation is important and prevails over other parameters in multi-objective analysis (e.g., visitors' comfort).

Case studies of monitoring campaigns and microclimate analysis of some historic libraries in Europe can be found in literature: Fabbri and Petrelli [11] report the results of a monitoring campaign of the Malatestiana Library, a historic library in Cesena, Italy, storing more than 300 manuscripts written in the 15th century, provided of no HVAC system. The results of the 3 -month monitoring campaign showed that there were no risks for the books, because of the perfect indoor conditions ensured by the envelope. In [5], Andretta et al. compare indoor microclimate with reference set points suggested by technical standards UNI 10829 and UNI 10586 to verify the current conditions of the books collections in the Classense Library in Ravenna, Italy. The campaign highlighted possible risks in some halls of the library due to too-high RH and too-high/too-low T, depending on the season: this is caused by the absence of a HVAC system. Sahin [6] presented the results of a monitoring campaign in Tire Necip Pasa Library, in Turkey. In this case, the manuscripts were found to undergo degradation due to high temperatures occurring during summer. Many researches are instead focused on the treatment methods after occurred damage (see, for example, [12]). 
Literature reports some methodologies for the improvement of the conservation conditions for artworks and cultural heritage, which often allow also a higher energy efficiency and a better human comfort for visitors: see, for example, $[13,14]$. In that sense, the two currently-used methodologies (fully described in the following sections) examine only some aspects of the artworks conservation problem and often consider also visitors' comfort (for a better experience of the museums) and energy efficiency. However, these methodologies may not fit well to historic libraries, as they are specific for museums. The two environments can be different, as books in historic libraries are rarely opened and accessible to the public and are often stored in almost stagnant air in bookcases. As previously mentioned, the main aim of historic libraries is the preservation of old and rare books, so the definition of a specific procedure for their preservation in these environments, now missing in literature, is important. It can be particularly important considering the large number of historic libraries, widespread especially in Europe and Asia.

\subsection{Research aim}

In this framework, a comprehensive new methodology aiming at identifying possible risks for books housed in historic libraries, based on microclimate data analysis, is presented. Besides, the procedure, through the evaluation of simple indices, considers the effects of spatial or temporal spans and the risks associated to biological and/or chemical degradation. Its application helps in the identification of the most suitable actions for the reduction of risks. In Section 3, the procedure is experimentally applied using the monitoring data of the Baroque Library of the University of Coimbra (Portugal), with records from December 2016 to July 2017.

\section{Methodology}

Scientific literature reports several methods for the study of risks for books: for example, culture-dependent analyses for the study of the airborne microorganisms and possible biological risks or infrared spectroscopy for chemical degradation. However, even though very precise, many of these methods identify risks only on the books that undergo a higher level of examination, which might not be suitable for large collections of historical books [15]. In this scenario, the suitability of microclimate for books preservation can be assessed through a continuous monitoring of the main involved parameters ( $\mathrm{T}$ and $\mathrm{RH}$ ) and the correlation of these data to the most typical damage mechanisms for paper.

Current literature proposes, in fact, two methods for the evaluation of microclimate suitability for books conservation in libraries: the microclimate method and the risk assessment method. In its classical application, reported in technical standards $[16,17]$ and conservators' books [18], the microclimate method highlights the importance of a constant and homogeneous thermal environment, warning against daily and spatial variations of $\mathrm{T}$ and $\mathrm{RH}$, which has been found to be dangerous for books integrity [19]. Literature [5,20-23] reports several cases of libraries (but also historic buildings and museums) where hygrothermal variation causes swelling and shrinking of the books and paper objects, even causing cracks. Thus, it is particularly important to study the hygrothermal temporal and spatial variation within a library.

The microclimate method provides reference values for daily and spatial variation not to be overpassed (see, for example, $[18,24]$ ).

The risk assessment method, on the other hand, presents models of the most typical mechanisms leading to damage of the paper, i.e. biological and chemical mechanisms. Biological damage occurs in presence of microbiological organisms that grow on paper, usually in high-humidity environments [4]. In particular, biological damage is related to fungal growth, which occurs for specific combinations of temperature and relative humidity and especially in presence of stagnant air. It is considered as one of the most serious types of damage, in terms of both visual degradation and change of substrate properties and characteristics, leading then to other types of degradation (e.g., sorption of particulate, and then chemical degradation) [25]. Literature [26-29] provides isopleth curves, which are T-RH curves over which spore germination or mould growth starts, depending on the substrate. Fig. 1.a shows, on a psychometric chart, the threshold values of temperature, specific humidity and relative humidity over which spore germination or mould growth occur on paper, according to Sedlbauer model $[30,31]$. As for chemical degradation mechanisms in paper, it is usually driven by acid hydrolysis [29], which leads to discoloration and embrittlement of paper and deterioration in text [4]. Chemical degradation is mainly related to changes in temperature. According to Michalski model [32], this deterioration mechanism can be modelled through a formula similar to Arrhenius equation. This formulation compares the effects of the actual indoor thermal environment and a benchmark microclimate $\left(20^{\circ} \mathrm{C}\right.$ for temperature and $50 \%$ for relative humidity $[25,32,33])$. This model is known as lifetime multiplier $(L M)$ and reads:

$$
L M_{i}=\left(\frac{R H_{r e f}}{R H_{i}}\right)^{1.3} \exp \left(\frac{E_{a}}{R}\left(\frac{1}{T_{i}+273.15}-\frac{1}{T_{r e f}}\right)\right)
$$

where $R H_{\text {ref }}$ and $T_{\text {ref }}$ are benchmark microclimate values, respectively $50 \%$ and $293.15 \mathrm{~K}, R$ is the ideal gas constant $(8.314 \mathrm{~J}$ $\left.\mathrm{mol}^{-1} \mathrm{~K}^{-1}\right), R H_{i}$ and $T_{i}$ (respectively in [\%] and $\left[{ }^{\circ} \mathrm{C}\right]$ ) are actual values of relative humidity and temperature, and $E a$ is the activation energy, equal for books to $100 \mathrm{~kJ} \mathrm{~mol}^{-1}$ [34].

If $L M$ is lower than 1, current microclimate can be dangerous for paper preservation. Fig. $1 \mathrm{~b}$ shows the iso- $L M$ curves, varying temperature and relative humidity, on the basis of the Michalski model. One can also evaluate the real lifetime horizon of the book, as many authors are in agreement on an average 500-year lifetime for paper [35].

\subsection{Description of the proposed procedure}

The proposed procedure is based on an intensive monitoring campaign, the aim of which is the identification of the hygrothermal profile of the rooms during a reference period. First, the rooms to be monitored should be identified, in accordance with the stakeholders. The duration of the monitoring campaign should be long enough to verify the presence of dangerous microclimate: UNI 10829 [24] suggests one whole year or, at least, a month for each season. This notwithstanding, the duration of the monitoring period can be defined on the basis of the availability of the owners. As for the position of the sensors, they should be located on the perimeter of the room, to verify the spatial span. Also, vertical distribution of hygrothermal parameters should be considered in case of high roofs, to verify the presence of stratification. Sensors should not be placed in proximity of sources or sinks of heat or moisture. A suggested time step for acquisition can be an hour fraction (e.g., 15 minutes): this time scale can enhance the detection of changes due to the presence of visitors, ventilation, opening of windows, HVAC operation. The objective of the sensors positioning is the creation of a "measuring grid", which gathers and saves indoor microclimate data. The measuring grid is 


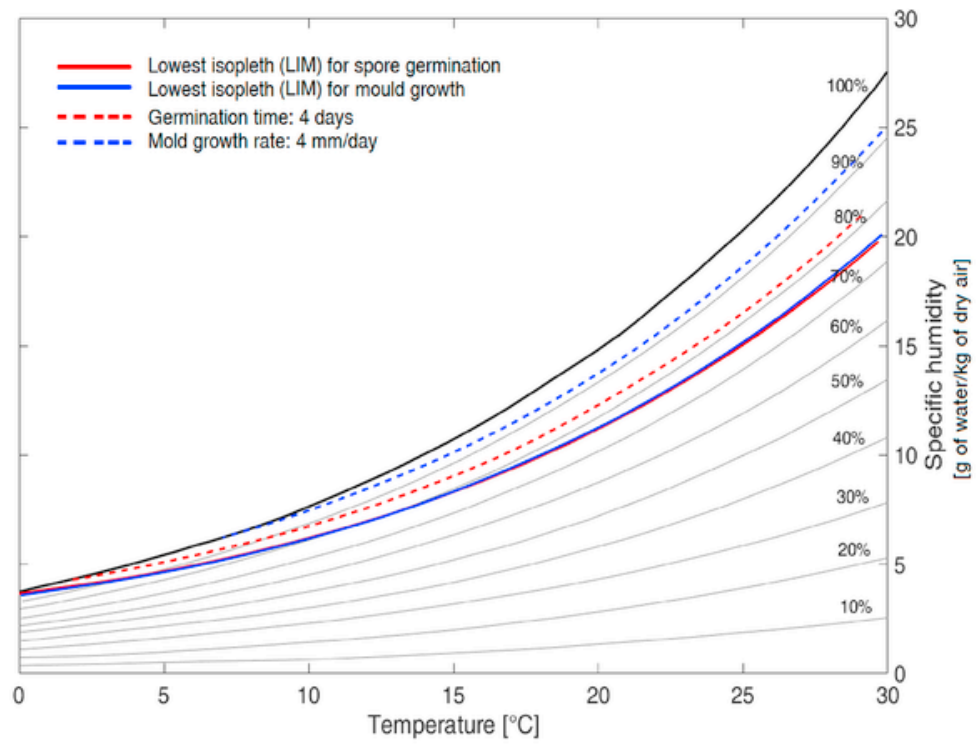

(a)

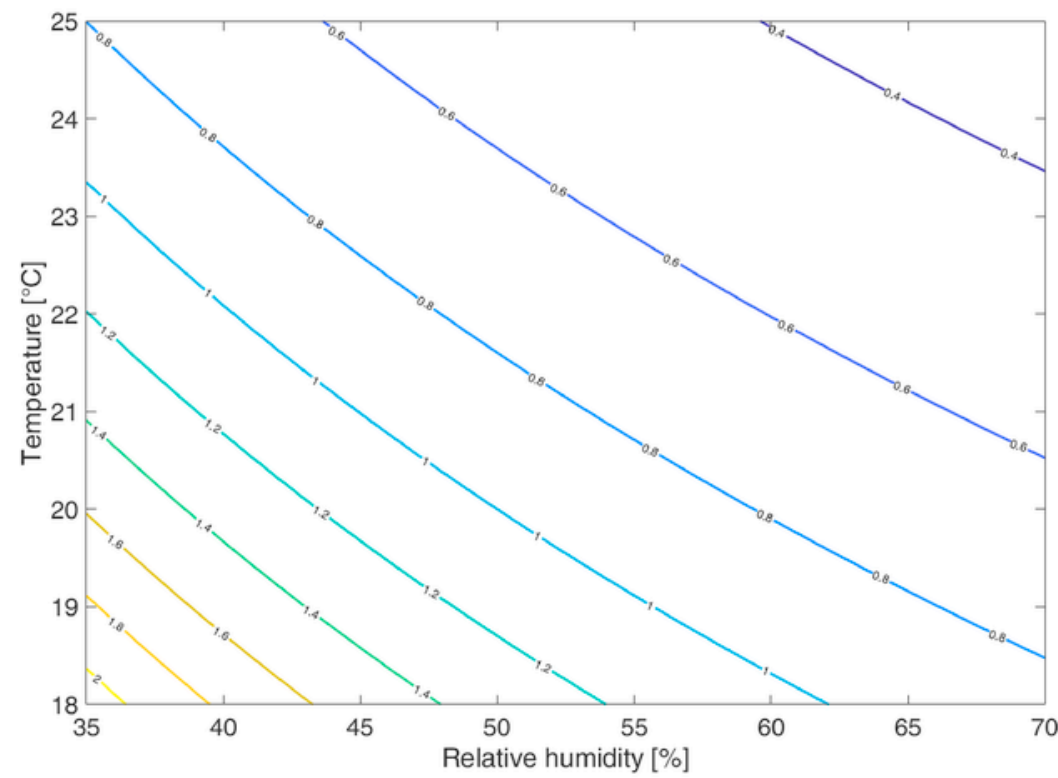

(b)

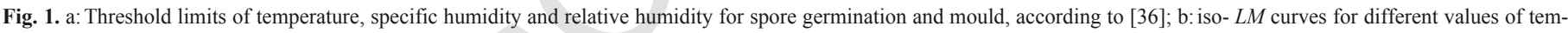
perature and relative humidity [32].

fundamental for the identification of local problems, hence for the implementation of local solutions, if necessary.

All the data acquired during the monitoring campaign are then analysed during the second phase of the procedure, with the concurrent evaluation of the risk indices, which check for possible risks for the stored books.

Fig. 2 shows a schematic representation of the proposed procedure:

- the first phase (green blocks) represents the preliminary phase of analysis of the library, with the selection of the rooms to be monitored, the identification of the monitoring period and the position of the sensors (definition of the measuring grid);
- the second phase (yellow block) corresponds to the monitoring campaign;

- the third phase (violet blocks) represents the data analysis, with the evaluation of the four indices discussed in Section 2.2.

On the basis of the results highlighted by the data analysis, it is possible to identify the most suitable actions and solutions for the improvement of the microclimate in the library, in order to reduce risks for books.

The procedure can also be applied to a "check-up" phase: after the implementation of the most suitable solutions, the monitoring of the hygrothermal parameters will help in the verification of the effectiveness of the chosen actions in reducing risks. Furthermore, in this sec- 


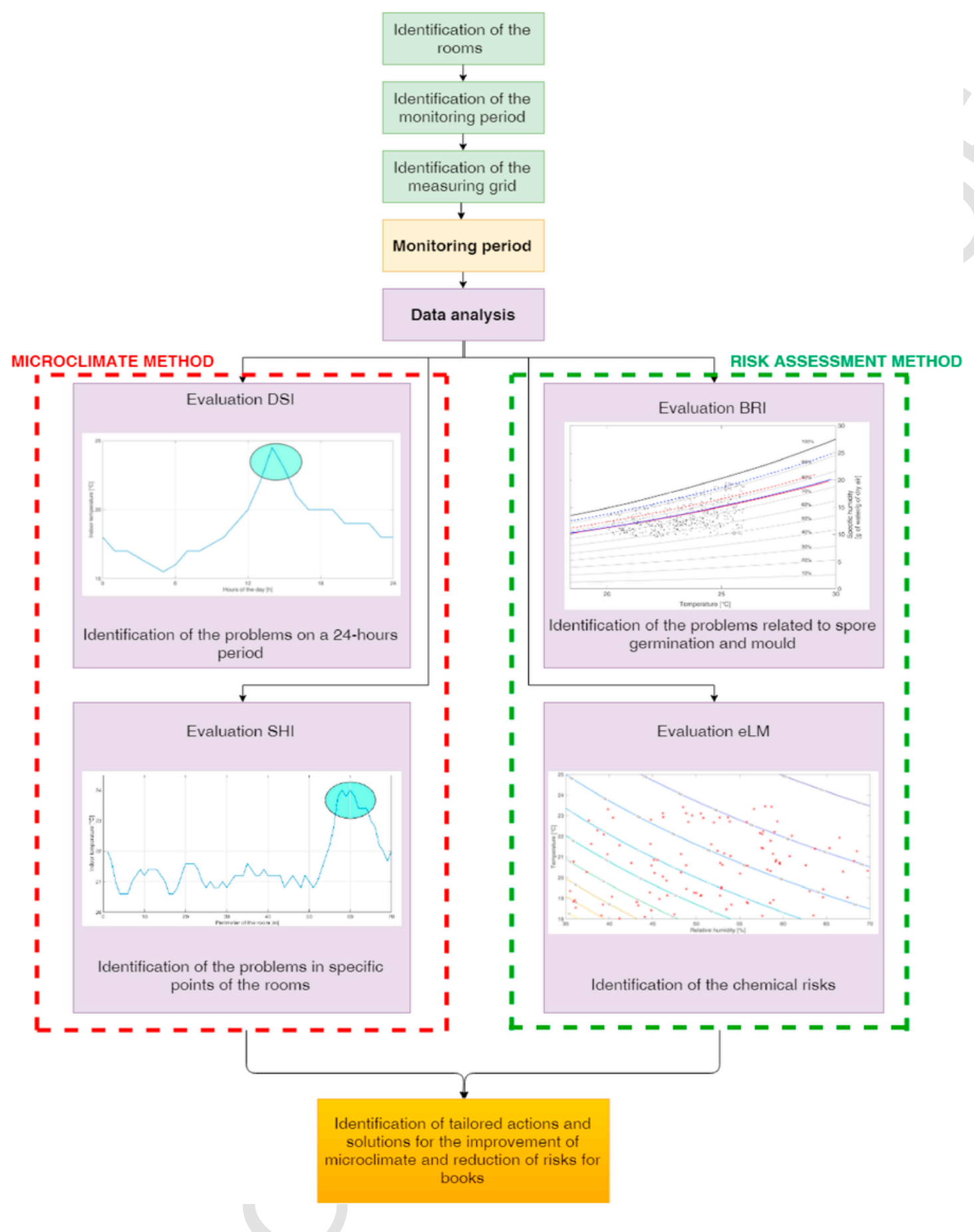

Fig. 2. Schematic representation of the proposed procedure.

ond phase, the monitoring campaign results can also be used to further improve, when possible, the indoor microclimate.

According to the definition given in EN 15898 [37], this procedure can be defined as a preventive conservation one, as it involves the immediate environment around the book to avoid damage and further invasive intervention.

\subsection{Evaluation of the risk indices}

The evaluation of the microclimate suitability after the monitoring campaign is based on the analysis of the gathered data and the estimation of four indices:

Daily Span Index (DSI) [38], which identifies the percentage of days in which the maximum values of temperature and relative humidity span do not exceed the allowed limits;

Spatial Homogeneity Index (SHI) [38], which identifies the percentage of time in which microclimate is sufficiently homogeneous in 
the defined volume, according to the allowed spatial variations:

- equivalent lifetime multiplier (eLM) [33], representing an equivalent value of the lifetime multiplier evaluated during the monitoring period, which considers $\mathrm{N}$ gathered values of temperature and relative humidity as follows in Eq. 2:

$$
e L M=\frac{1}{\frac{1}{N} \sum_{i=1}^{N}\left(\frac{1}{L M_{i}\left(T_{i}, R H_{i}\right)}\right)}
$$

- an $e L M$ value higher than 1 means that there is no chemical risk for books. In the eLM evaluation, $L M$ is calculated as in Eq. 1;

- biological Risk Index ( $B R I)$, defined as the percentage of time in which the lowest isopleth for spore germination is overpassed.

The microclimate method applies for the first two indices, using for example [18] and [24] as reference for the evaluation of DSI and $S H I$, respectively. These references suggest a maximum daily span of $2{ }^{\circ} \mathrm{C}$ and $8 \%$ and a maximum spatial variation of $2{ }^{\circ} \mathrm{C}$ and $5 \%$, for temperature and relative humidity, respectively. The risk assessment method is instead at the base of the $e L M$ and $B R I$ evaluation.

The authors would like to stress that the importance of both methodologies for the identification of criticalities in historic libraries; in fact, a concurrent use of these methodologies is proposed here, whereas in literature, researchers tend to use only one of them in their analysis. If used separately, the two methodologies point out only some aspects of the preservation problem, nonetheless, both methods are necessary for a comprehensive assessment of the possible risks.

The following example, considering eLM and DSI, helps clarifying this aspect. Please consider Fig. 3, where two hypothetical set of measurements are shown: the first one (represented by the black circle markers), with mean values for $\mathrm{T}$ and $\mathrm{RH}$, respectively, $21.0^{\circ} \mathrm{C}$ and $55 \%$, daily $\mathrm{T}$ span equal to $1.4 \mathrm{~K}$ and daily $\mathrm{RH}$ span equal to $6 \%$; the second one (represented by the red cross markers), with mean value for $\mathrm{T}$ and $\mathrm{RH}$, respectively, $19.5^{\circ} \mathrm{C}$ and $45 \%$, daily $\mathrm{T}$ span equal to $3.0 \mathrm{~K}$ and daily $\mathrm{RH}$ span equal to $10 \%$. If only the microclimate method is used for the analysis of the first set, one can conclude the absence of risk for books, as the microclimate is sufficiently constant during the monitoring period. The risk assessment method, however, highlights possible chemical risks (eLM around 0.8). Considering now the second set of measurements, if only the risk assessment method is used, one can conclude that there are no risks for books, as eLM is higher than 1. However, the application of the microclimate method points out that the microclimate is not sufficiently constant in the room. Thus, the application of both methodologies helps in a definition of a sound overview of the possible risky situation for books; furthermore, it also highlights which solutions would be more appropriate to apply.

The proposed procedure has been applied to a case study.

\section{Application to a case study}

\subsection{Object of study}

The Baroque Library of the University of Coimbra (UC) is located in the "heart" of the historic centre of the University, the courtyard of the Palace of Schools (Fig. 3). The origins of this library go back to the 18th century, when, in 1716 , the rector of the University, Nuno Silva Teles, asked the Crown to build a library that would serve the institution. D. João V, then King of Portugal, accepted the request, and ordered by royal decree on October 31 st of that year, the construction of the one that later was named in his honour as Biblioteca Joanina. The works began the following summer and lasted until 1728 [39], using the ruins of a 15 th century prison as foundation [40]. Its area (circa $1250 \mathrm{~m}^{2}$ ) is distributed along three floors: the Noble floor, the Intermediate Floor, and the Academic Prison ("which worked here from 1773 until 1834") [9]; it is a reflection of prosperity, similar to baroque cathedrals, with richly ornamented oak-wood shelves, ceilings decorated with trompe-l'oeil, arches and paintings. It is an independent and unique building, relevant not only for its architecture and internal decorations, but also because of the intangible heritage within the 40 thousand housed books (dating from the 16th, 17th, and 18th centuries). It worked as a place of study from 1777 until the mid of last century, when the new General Library building was opened (1962) [9].

The first studies on the Baroque Library, developed until 2010, were focused on its environmental conditions, in particular on the effects of its thick masonry walls [41-43] (some of them are more than

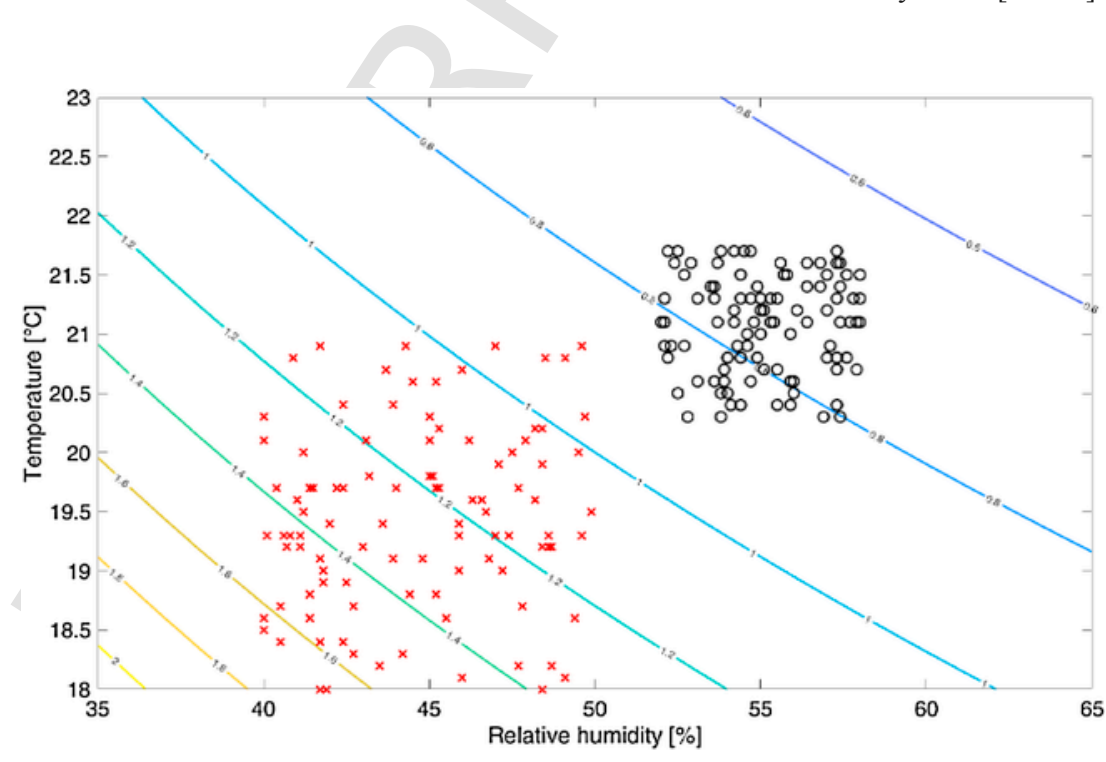

Fig. 3. Example of concurrent application of the two methodologies. 
2-metre wide). Nonetheless, the current conditions of the Library have been significantly altered on the account of the increase of tourist flows (i.e. augmented number of people indoors and frequency of door openings). In 2012, the Library received up to 120,000 visitors, in 2013 the historic centre of the University was officially declared as a World Heritage, and in 2017 it reached over half-million visitors. Objectively, during the high-peak touristic season (from the beginning of March until the end of September), this space opens its doors every 20 minutes, from 9 a.m. to 8 p.m., receiving up to 60 people each time.

On the basis of this new picture, concerned by the impacts on the conservation of such tangible and intangible heritage, the Rectorate of the UC began a research project addressing the indoor environmental characterization of such space and the identification of potential hazard situations. Notwithstanding the richness of the interior wood value, within the present paper, the focus is addressed to paper conservation properties and risk assessment for books, still housed in a naturally ventilated environment.

\subsection{Microclimate monitoring}

Indoor air temperature (expressed in ${ }^{\circ} \mathrm{C}$ ) and relative humidity (expressed in \%) were monitored in the Baroque Library between December 16th, 2016 and July 6th, 2017 Fig. 4. In several studies, microclimate parameters are recorded every 15 minutes. Herein, they were intentionally registered every 5 minutes with HOBO UX100-003 data-loggers [44], so that the entire tourist visiting period and door opening/closing was properly embraced: tourists enter the library every 20 minutes, therefore, several records were registered during each period. The technical characteristics of the data-loggers are shown in Table 1. As in [33], outdoor climate data were obtained from the nearest weather station, conveniently located less than $100 \mathrm{~m}$ away.

Aiming at a proper microclimate characterization, both vertically and horizontally, giving the architecture of the Library and an equal distribution of the equipment, twelve data-loggers were distributed, as observed in Fig. 5. Summarily, six data-loggers were installed at "ground floor" (GF in the following) and other six were installed at mezzanine floor or "first floor" (FF), thus creating the measuring grid.

Since mid-January, one of the equipment located on the GF (highlighted with a black dashed circle in Fig. 5) stopped recording data. Nevertheless, all the other equipment worked properly for the whole monitoring campaign, except for the duration of the scheduled main- tenance, from March 14th to April 3rd: this period was used for data transfer and software update of the equipment. For this analysis, it was identified:

- a first monitoring period (MP1), December $17^{\text {th }}-$ March $14^{\text {th }}($ designated as 'winter period');

- a second monitoring period (MP2), April $3^{\text {rd }}-$ July $6^{\text {th }}$ (designated as 'spring/summer period').

\subsection{Data analysis and results}

\subsubsection{Evaluation of DSI and SHI ("microclimate method")}

As the Baroque Library has no HVAC system, a higher external climate variation also reflects in a higher indoor climate variation. The thick walls revealed to be effective in smoothing and delaying the changes of the outdoor climate, however, in spring-summer time, the daily variation of $\mathrm{T}$ was higher, probably caused by the solar gains through the windows.

The differences between the winter and spring-summer daily span inside the Library are also highlighted through the DSI evaluation. The graphical representation of this index, for the two floors and the two monitoring periods, is shown in Figs. $6 \mathrm{a}$ and b; the numerical values of $D S I$ are reported on the right corner of each figure. A higher daily variation was verified during the MP2.

Spatial Homogeneity Index (SHI) was also evaluated and its graphical representation is shown in Fig. $6 \mathrm{c}$ and $\mathrm{d}$ for the MP1 and the MP2, for both the GF and FF. Alike DSI values, the $S H I$ values are also reported on the top right corner of each figure. Concerning temperature spatial variation, good results were found in both monitoring periods. Relative humidity values, instead, showed a higher variation: in particular, the maximum difference was found between the entrance (data-loggers \#FF1 and \#FF 6, data-logger \#GF1) and the opposite wall (data-loggers \#FF3 and \#FF4, data-loggers \#GF3 and \#GF4), where higher RH was found.

More in-depth analyses have been conducted, focusing on the characterisation of the microclimate profiles. Daily and weekly periodicities, presence of stratification, and spatial gradients along the perimeter have been sought: the results of these further analyses are shown in the Supplementary Material submitted on Data in Brief, together with additional post-processing of the monitoring data [45].

Summarizing the results of the application of the "microclimate method", it can be concluded that, during spring-summer, the solar gains influence the daily span: in fact, a low DSI was found during the MP2. As for the spatial variation, significant differences were

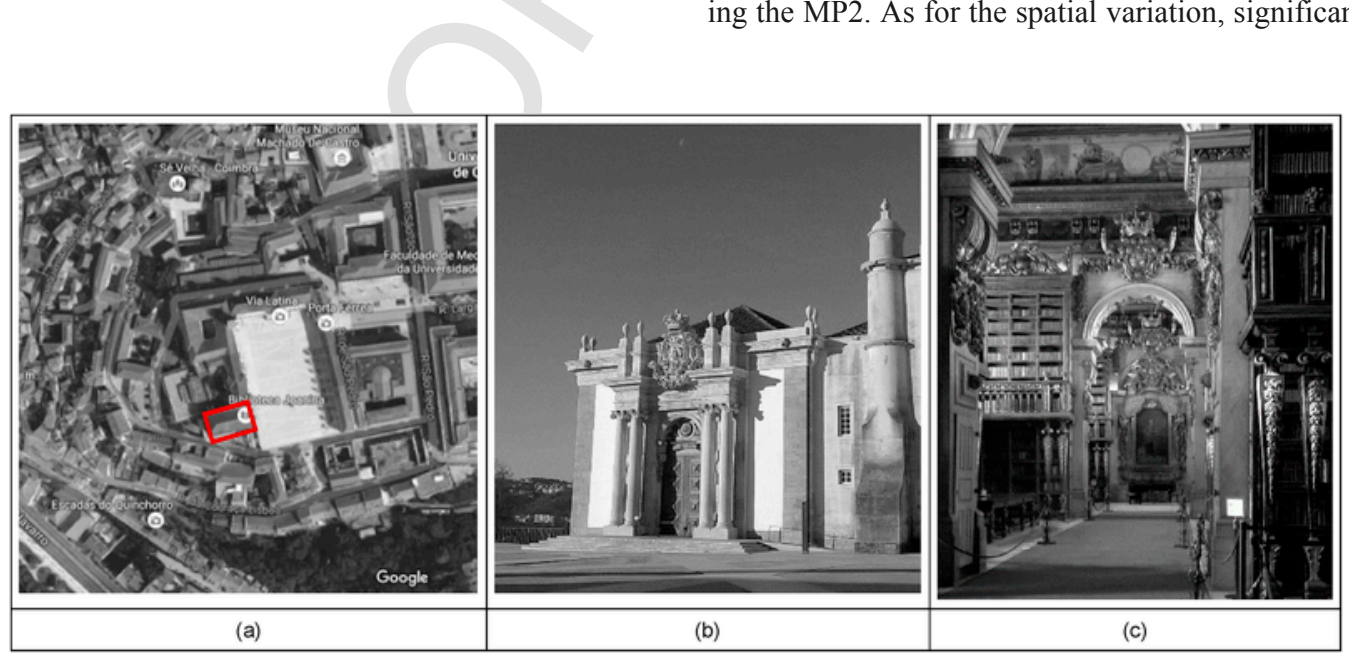

Fig. 4. a: Location of the Library [Google Maps (2016)]; b: external view of the Library East façade; c: internal view of the Library. 
Table 1

Technical characteristics of the data-loggers.

\begin{tabular}{|c|c|c|}
\hline Sensor/Parameter & $\begin{array}{l}\text { Measuring } \\
\text { range }\end{array}$ & Accuracy \\
\hline Temperature & $\begin{array}{l}-20^{\circ} \text { to } \\
70^{\circ} \mathrm{C}\end{array}$ & $\pm 0.21^{\circ} \mathrm{C}$ from $0^{\circ}$ to $50^{\circ} \mathrm{C}$ \\
\hline $\begin{array}{l}\text { Relative } \\
\text { humidity }\end{array}$ & $\begin{array}{l}15 \% \text { to } \\
95 \%\end{array}$ & $\begin{array}{l} \pm 3.5 \% \text { from } 25 \% \text { to } 85 \% \text { including hysteresis } \\
\text { at } 25{ }^{\circ} \mathrm{C} \text {; below } 25 \% \text { and above } 85 \%, \pm 5 \% \\
\text { typical }\end{array}$ \\
\hline
\end{tabular}

found between the main entrance and the opposite wall. This was probably due to the lower effect of ventilation.

\subsubsection{Evaluation of BRI and eLM ("risk assessment method")}

The second part of the data analysis regarded the evaluation of the $B R I$ and $e L M$, which are the two indices for the risk assessment method evaluating the biological and chemical risks. From the results of the microclimate method, the following problems were highlighted:

- potential risks due to high humidity were found in the wall opposite the entrance;

- a high daily span was found during the MP2, probably due to the influence of higher solar gains.

To assess the risk for books, BRI and eLM were also evaluated. In particular, during the MP1, BRI was evaluated separately for the five

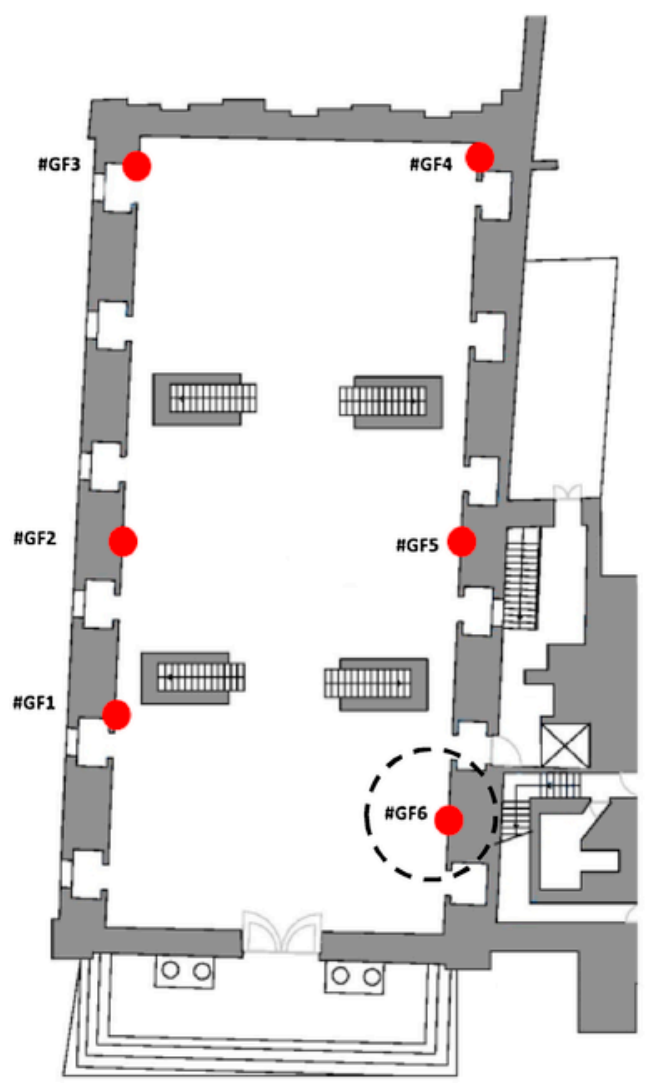

(a)

(b) data-loggers at the GF and for the six sensors at the FF. The analysis has pointed out that the germination threshold curve has been overpassed at the GF, in correspondence of the data-loggers \#GF3 and \#GF4, which are the farthest from the main entrance door.

Fig. 7 reports the gathered data for each GF sensor, compared to the threshold curve. In any case, BRI was lower than $5 \%$, which is not sufficient for mould growth, but highlights that risk is present. The black diamond markers represent the mean daily T and RH data. It is worth noting that increasing the external air ventilation rate would not usefully reduce the biological risk: in fact, as observed in the five figures, the mean daily external climate data, which is represented by the red cross markers, evidenced even higher values of relative humidity outdoors.

The other evaluated index was the $e L M$, related to chemical risk; the indices are evaluated using the average of all data-loggers. The values are reported in Table 2. The eLM value has also been evaluated separately for each data-logger, to assess if chemical risk was higher in some areas of the Library. However, this analysis has shown that the chemical risk is homogeneous within the Library. During the MP1, the $e L M$ values were higher than 1 at both floors, highlighting that current microclimate did not entail chemical risks for books. In the MP2, instead, temperature and relative humidity values hamper paper preservation, as the $e L M$ was lower than 1 . On an annual period, the $e L M$ value points out that chemical risk is minimal but present. This analysis highlights that books are exposed to biological and chemical risks, which can hamper their conservation.

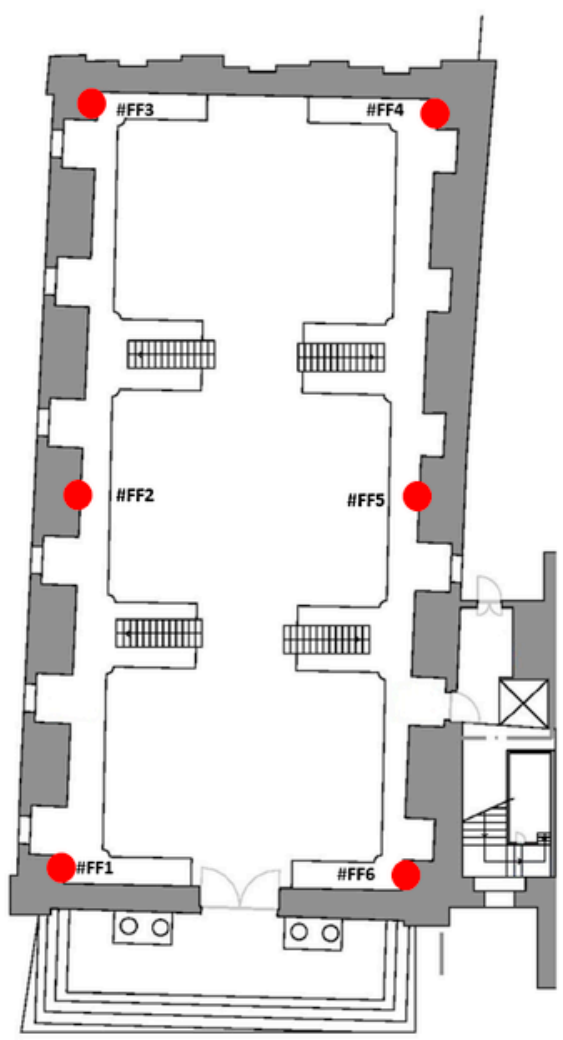

Fig. 5. Sensors location in the library: a: ground floor (GF); b: first floor (FF). 


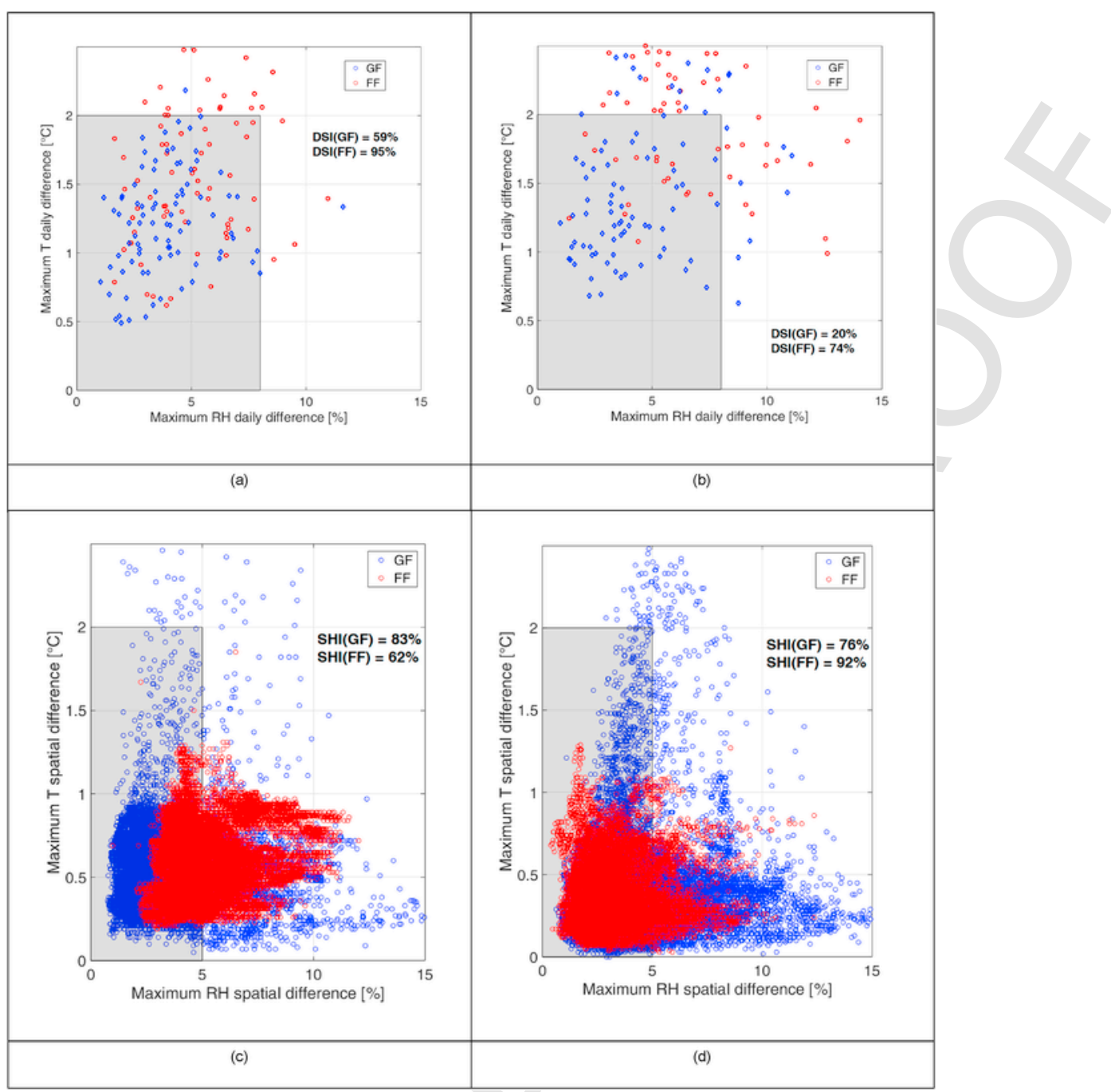

Fig. 6. Graphical representation of the two microclimate method indices: a: DSI, referring MP1, b: DSI, referring MP2, c: SHI, referring MP1, d: SHI, referring MP2.

\subsection{Error analysis}

An error analysis is herein reported, evaluating the four indices, assuming that the data-loggers have their own accuracy in the measurement of temperature and relative humidity. The characteristics of the data-loggers were previously shown in Table 1.

First, a moving average filter to evaluate the moving standard deviation $(M S D)$ of the acquired data was used. This value gave an estimation of the actual accuracy of the sensors. Then, a Monte Carlo method was performed. A random error was applied to the gathered hygrothermal data, using a normal distribution with nil mean and standard deviation equal to half the accuracy. Using these generated indoor climatic data, the three indices DSI, SHI and BRI are evaluated. This procedure was repeated for a significant number of tests: no variations were found (in terms of the indices) if 100 tests or 1000 tests were performed, pointing out a substantial convergence of the results of the Monte Carlo method. The results of this analysis showed that $S H I$ and $D S I$ indices slightly decrease for the application of the random error: this, in fact, amplifies the possibility of exceeding the maximum hygrothermal limits (a positive error applies to some data-logger readings, a negative error to some other readings, thus increasing the difference between them). No relevant difference, instead, was shown regarding the BRI analysis. Table 3 shows the results of this Monte Carlo error analysis.

The traditional propagation of errors expression [46] was used, instead, for the evaluation of the $e L M$ uncertainty from the uncertainties of the temperature and relative humidity data-loggers. As in the BRI evaluation, the error analysis showed no relevant differences on the $e L M$ values (see Table 4).

\subsection{Discussion}

The combined analysis ("microclimate method" and "risk assessment method") has highlighted that the indoor microclimate in the Baroque Library presents some risks for books conservation. The application of an in-depth monitoring campaign and the evaluation of the proposed indices has pointed out that the absence of HVAC system represents a limit for the maintenance of suitable conditions in the rooms: in particular, during the spring-summer months, the daily variation of hygrothermal parameters is mainly caused by the solar irradiance through the windows. Another problem is the spatial inhomogeneity, highlighted by both the $S H I$ and the BRI analysis. In particular, the risk is due to the RH values higher than $89 \%$, showing possible mould growth, especially for the books stored in the wall opposite the entrance door. Finally, a minimal chemical risk can also be 

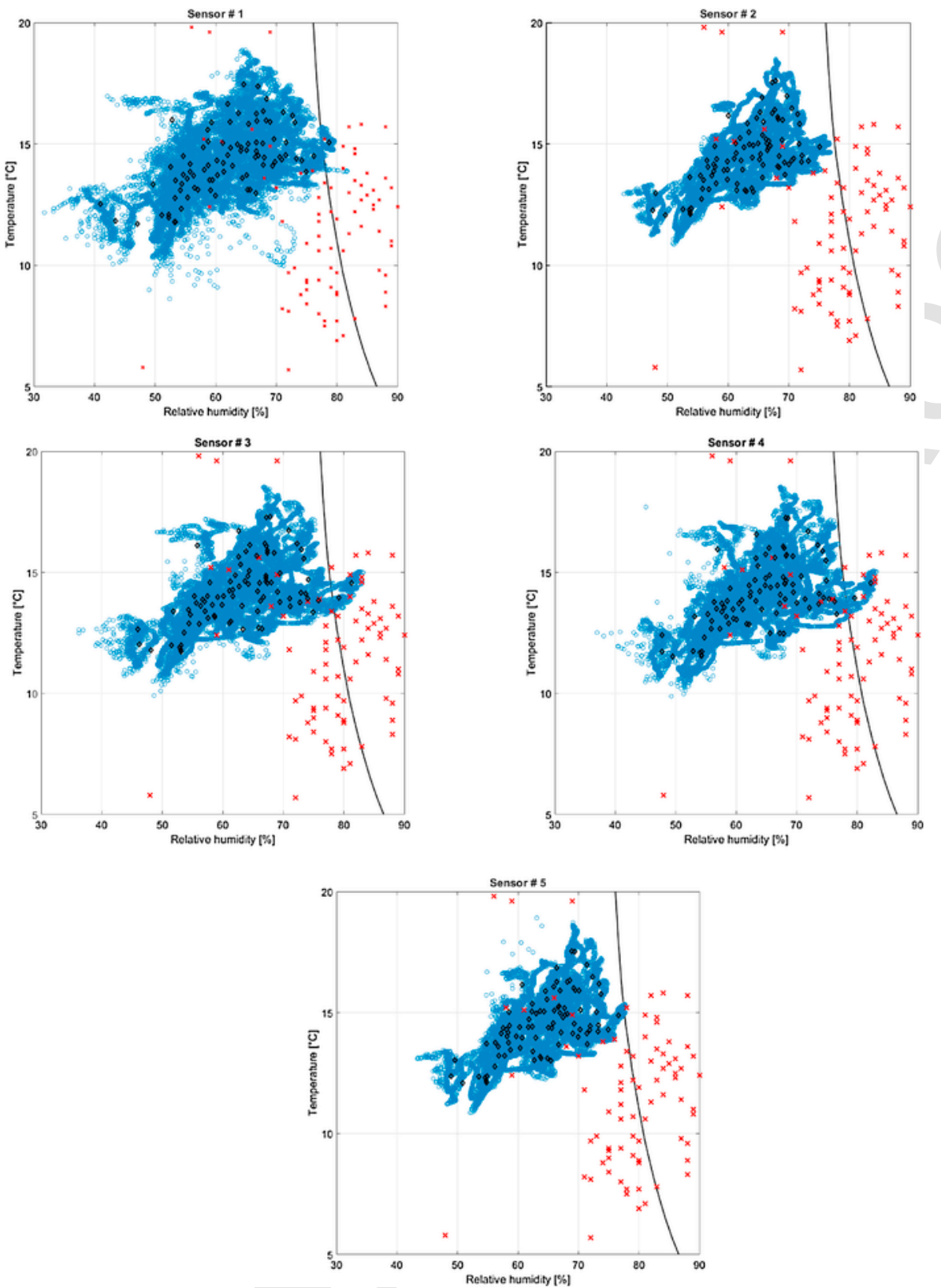

Fig. 7. Biological risk using the data gathered by the five sensors at ground floor, during the first monitoring period.

Table 2

$e L M$ values for ground and first floor.

\begin{tabular}{lll}
\hline & GF & FF \\
\hline MP1 & 1.61 & 1.64 \\
MP2 & 0.61 & 0.62 \\
Total & 0.88 & 0.90 \\
\hline
\end{tabular}

pointed out, which is stronger in the spring-summer period, when higher temperatures in the library were found. This issue can be considered related to the daily variation, which is higher in summer. From this analysis, it is possible to identify the most suitable action to reduce risks and damage for books. Two types of mildly-intrusive solutions can be proposed:
- reduction of the solar gains during the summer period (e.g., through shutters): this solution will reduce indoor temperature, thus increasing $e L M$ and $D S I$ in the summer period;

- use of local dehumidifiers for the reduction of indoor relative humidity: this solution will reduce the effect of high relative humidity at the wall opposite the entrance, reducing the biological risk.

Currently, the microclimate has negative impacts also on the furniture and wooden objects present in the Library. Some of the methods to evaluate the risks for those materials are similar to those used for books: Sedlbauer's model for mould growth (with different values of $\mathrm{T}$ and $\mathrm{RH}$, as the structure of these materials hinders the growth, so biological risks are lower [36]); lifetime multiplier for chemical risks (using an activation energy of $70 \mathrm{~kJ} / \mathrm{mol}$ [34]). As for the spatial distribution, the same threshold values apply [16], while for daily 
Table 3

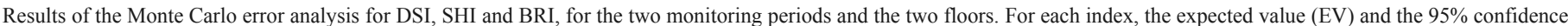
interval $(95 \% \mathrm{CI})$, obtained by the Monte Carlo analysis, are reported. The monitoring campaign value (MCV) of each index is also showed.

\begin{tabular}{|c|c|c|c|c|c|c|c|c|c|c|}
\hline & & DSI & & & SHI & & & BRI & & \\
\hline \multirow{3}{*}{ MP1 } & & $\mathrm{EV}$ & $95 \% \mathrm{CI}$ & $\mathrm{MCV}$ & EV & $95 \% \mathrm{CI}$ & $\mathrm{MCV}$ & EV & $95 \% \mathrm{CI}$ & $\mathrm{MCV}$ \\
\hline & GF & $56 \%$ & $51.5-60.0 \%$ & $59 \%$ & $80 \%$ & $79.7-83.5 \%$ & $83 \%$ & $4 \%$ & $3.5-4.2 \%$ & $4 \%$ \\
\hline & $\mathrm{FF}$ & $92 \%$ & $90.2-95.7 \%$ & $95 \%$ & $59 \%$ & $58.0-60.0 \%$ & $62 \%$ & $0 \%$ & $0.0-0.2 \%$ & $0 \%$ \\
\hline \multirow[t]{2}{*}{ MP2 } & GF & $19 \%$ & $18.5-21.8 \%$ & $20 \%$ & $74 \%$ & $73.6-75.3 \%$ & $76 \%$ & $0 \%$ & - & $0 \%$ \\
\hline & $\mathrm{FF}$ & $70 \%$ & $68.5-73.5 \%$ & $74 \%$ & $91 \%$ & $90.5-92.0 \%$ & $92 \%$ & $0 \%$ & - & $0 \%$ \\
\hline
\end{tabular}

Table 4

Results of the propagation of errors analysis for eLM.

\begin{tabular}{lll}
\hline & GF & FF \\
\hline MP1 & $1.61 \pm 0.07$ & $1.64 \pm 0.07$ \\
MP2 & $0.61 \pm 0.03$ & $0.62 \pm 0.03$ \\
\hline
\end{tabular}

variation, a $8-10 \%$ of $\mathrm{RH}$ variation [18] and a $1.5^{\circ} \mathrm{C}$ for $\mathrm{T}$ variation [16] are suggested. The evaluation of the indices for the risks applied to the furniture and wooden objects has pointed out possible risks also for these materials $(e L M=1.29$ for MP1 but $e L M=0.68$ for MP2; $S H I=73 \%$ for MP1 and $S H I=84 \%$ for MP2; $D S I=58 \%$ for MP1 and $D S I=36 \%$ for MP2), so the implementation of the chosen solutions can lead to an improving of conservation conditions for them.

A second monitoring campaign after the implementation of these solutions can verify the suitability of the actions in the reduction of risks for books.

\section{Conclusions}

This work presented a comprehensive procedure for the identification of possible risks for books conservation in historic libraries, also pointing out which can be the best solutions to avoid damage. This new procedure is based on a detailed microclimate analysis and evaluation of several risk assessment indicators, which guide the researchers on the identification of the most serious criticalities. The use of a spatially distributed monitoring campaign allows the analysis of large collections of books. The creation of a measuring grid and the consequent data analysis ensures the individuation of local solutions. This aspect is crucial in historic buildings, as it limits the intrusiveness of the retrofit solutions; moreover, it reduces costs and modifies indoor microclimate only where risk for books preservation is present. The proposed procedure can be used as a preventive conservation procedure, in "diagnosis" phase (identification of possible risks and of most suitable solutions) but also in "check-up" phase (after the implementation of the solutions, verification of the reduction of risks and analysis of the possibility of further improvement). It can be successfully used by conservators, to reduce risks for the books using the most suitable solution according to specific constraints (e.g., economic constraints, protection of the historic value of the building).

The application to a real case study has highlighted the potential of the procedure. The case study was a historic library located in Coimbra, where the current environmental conditions of this recent touristic attraction were deeply investigated: microclimate monitoring was run over a 6-month period. This new procedure has unveiled that, within this library, books are potentially exposed to biological and chemical risks and that an immediate action is required. In particular, it was found that solutions are needed to reduce the high daily variation during the summer period, which increases chemical risks, and to reduce relative humidity on specific points of the library. Lim- ited local actions should be taken to limit these risks and improve book preservation in this historical library.

The authors believe that this new procedure is replicable to other historic libraries: not only those libraries with similar features to our case study, but also all the historic libraries which were rarely visited in the past and are now a touristic attraction. In these libraries, in fact, the change of the indoor microclimate can represent a potential hazard for book preservation, so actions should be taken to preserve this heritage. In future, the proposed methodology might be extended, also accounting on the risks associated with the presence of airborne pollutants. For the present and forthcoming works, the authors will monitor and analyse the implementation of the proposed solutions to the Baroque Library in Coimbra, together with a study on the effects of these actions on the visitors' thermal comfort. Furthermore, the proposed procedure will be applied to other historic libraries, such as the Library of the Scuola Normale Superiore, in Pisa, which hosts antique and rare works and is one of the largest in Europe.

\section{Acknowledgments}

The authors are grateful to the Rectorate of the University of Coimbra and to the General Library of the University for having promoted and facilitated this work. The presented work is framed under the Energy for Sustainability Initiative of the University of Coimbra and UC Project SUSpENsE - Sustainable built Environment under Natural Hazards and Extreme Events.

\section{References}

[1] G. Fantuzzi, F. Fantuzzi, G. Aggazzotti, G. Righi, E. Cavazzuti, L. Predlerl, Indoor air quality in the university libraries of Modena(Italy), Sci. Total Environ. 193 (1996) 49-56.

[2] E. Righi, G. Aggazzotti, G. Fantuzzi, V. Ciccarese, G. Predieri, Air quality and well-being perception in subjects attending university libraries in Modena (Italy), Sci. Total Environ. 286 (2002) 41-50, https://doi.org/10.1016/ S0048-9697(01)00960-3.

[3] Z. Wang, L. Chen, G. Zhang, Investigation on indoor air quality in university libraries in Xi' an, 4th Int. Conf. Bioinforma. Biomed. Eng. (2010) 1-4, https://doi. org/10.1109/ICBBE.2010.5518179.

[4] ASHRAE, Museums, Galleries, Archives and Libraries, in: ASHRAE Handb. Heating, Vent. Air-Conditioning Appl., SI Edition, ASHRAE, Atlanta, 2003.

[5] M. Andretta, F. Coppola, L. Seccia, Investigation on the interaction between the outdoor environment and the indoor microclimate of a historical library, J. Cult. Herit. 17 (2016) 75-86, https://doi.org/10.1016/j.culher.2015.07.002.

[6] C.D. Sahin, T. Coşkun, Z.D. Arsan, G. Gökçen Akkurt, Investigation of indoor microclimate of historic libraries for preventive conservation of manuscriptsCase Study: Tire Necip Paşa Library, İzmir-Turkey, Sustain. Cities Soc. 30 (2017) 66-78, https://doi.org/10.1016/j.scs.2016.11.002.

[7] L. Schibuola, M. Scarpa, C. Tambani, CO2-based ventilation control in energy retrofit: an experimental assessment, Energy. 143 (2018) 606-614, https://doi. org/10.1016/j.energy.2017.11.050.

[8] Biblioteca Angelica, Bibliotheca Angelica, (2018).

[9] UC, UC|Visiting the UC|Baroque Library, (2014).

[10] Biblioteca Casanatense, Biblioteca Casanatense, (2018).

[11] K. Fabbri, M. Pretelli, Heritage buildings and historic microclimate without HVAC technology: Malatestiana Library in Cesena, Italy, UNESCO Memory of the World, Energy Build. 76 (2014) 15-31, https://doi.org/10.1016/j.enbuild. 2014.02.051. 
[12] I. Alexopoulou, S. Zervos, Paper conservation methods: an international survey, J. Cult. Herit. 21 (2016) 922-930, https://doi.org/10.1016/j.culher.2016.04.001.

[13] E. Schito, P. Conti, D. Testi, Multi-objective optimization of microclimate in museums for concurrent reduction of energy needs, visitors' discomfort and artwork preservation risks, Appl. Energy. 224 (2018) https://doi.org/10.1016/j. apenergy.2018.04.076.

[14] E. Lucchi, Multidisciplinary risk-based analysis for supporting the decision-making process on conservation, energy efficiency, and human comfort in museum buildings, J. Cult. Herit. 22 (2016) 1079-1089, https://doi.org/10.1016/ j.culher.2016.06.001.

[15] K. Dzinavatonga, K. Bharuth-Ram, T.R. Medupe, Mössbauer spectroscopy analysis of valence state of iron in historical documents obtained from the $\mathrm{Na}$ tional Library of South Africa, J. Cult. Herit. 16 (2015) 377-380, https://doi.org/ 10.1016/j.culher.2014.06.004.

[16] Ente Italiano di Normazione, UNI 10829. Condizioni ambientali di conservazione, UNI. (1999).

[17] Ente Italiano di Normazione, UNI 10586. Condizioni climatiche per ambienti di conservazione di documenti grafici e caratteristiche degli alloggiamenti., (1997).

[18] G. Thomson, In: 2nd ed., The Museum Environment,, 330, Butter Worths, London, 1986https://doi.org/10.1016/B978-0-7506-1266-1.50010-X.

[19] M. Andretta, F. Coppola, A. Modelli, N. Santopuoli, L. Seccia, Proposal for a new environmental risk assessment methodology in cultural heritage protection, J. Cult. Herit. 23 (2017) 22-32, https://doi.org/10.1016/j.culher.2016.08.001.

[20] C. Pasquarella, C. Balocco, G. Pasquariello, G. Petrone, E. Saccani, P. Manotti, M. Ugolotti, F. Palla, O. Maggi, R. Albertini, A multidisciplinary approach to the study of cultural heritage environments: experience at the Palatina Library in Parma, Sci. Total Environ. 536 (2015) 557-567, https://doi.org/10.1016/j. scitotenv.2015.07.105

[21] D. Chiriu, P.C. Ricci, G. Cappellini, C.M. Carbonaro, Ancient and modern paper: Study on ageing and degradation process by means of portable NIR $\mu$-Raman spectroscopy, Microchem. J. 138 (2018) 26-34, https://doi.org/10.1016/j. microc.2017.12.024.

[22] M. De La Paz Diulio, M.G.S. Cruz, A. Gómez, Preventive conservation plan for library buildings in La Plata, Argentina, Energy Procedia. 78 (2015) 1293-1298, https://doi.org/10.1016/j.egypro.2015.11.143.

[23] E. Schito, P. Conti, D. Testi, Robust microclimate control for artwork preservation in response to extreme climatic conditions: simulation of museum halls for temporary exhibitions with a validated dynamic tool, in: IOP Conf, Ser. Mater. Sci. Eng. (2018) https://doi.org/10.1088/1757-899X/364/1/012008.

[24] UNI, UNI 10829 Beni di interesse storico e artistico - Condizioni ambientali di conservazione - Misurazione ed analisi, (1999).

[25] H.E. Silva, F.M.A. Henriques, T.A.S. Henriques, G. Coelho, A sequential process to assess and optimize the indoor climate in museums, Build. Environ. 104 (2016) 21-34, https://doi.org/10.1016/j.buildenv.2016.04.023.

[26] A.A. Reis-menezes, W. Gambale, M. Cintra, M. Aiko, International Biodeterioration and Biodegradation Accelerated testing of mold growth on traditional and recycled book paper, Int. Biodeterior. Biodegradation. 65 (2011) 423-428, https: //doi.org/10.1016/j.ibiod.2011.01.006.

[27] T. Kalamees, A. Väli, L. Kurik, M. Napp, E. Arümagi, The influence of indoor climate control on risk for damages in naturally ventilated historic churches in cold climate the influence of indoor climate control on risk for damages in naturally ventilated historic churches in cold climate, Int. J. Archit. Herit. 10 (2016) 486-498, https://doi.org/10.1080/15583058.2014.1003623.
[28] A. Oetari, T. Susetyo-salim, W. Sjamsuridzal, D. Chitra, T. Prasetia, Occurrence of fungi on deteriorated old dluwang manuscripts from Indonesia, Int. Biodeterior. Biodegradation. 114 (2016) 94-103, https://doi.org/10.1016/j.ibiod.2016. 05.025 .

[29] American Society of Heating Refrigerating and Air-Conditioning Engineers, ASHRAE Fundamentals Handbook, Atlanta, 2013.

[30] K. Sedlbauer, Prediction of mould fungus formation on the surface of and inside building components, Fraunhofer Institute Buid. Phys. (2001).

[31] K. Sedlbauer, M. Krus, A new model for mould prediction and its application in practice, in: 2nd Int, Conf. Buid. Phys. (2003) 921-927.

[32] S. Michalski, Double the life for each five-degree drop, more than double the life for each halving of relative humidity, in: 13th Trienn. Meet. (Rio Janeiro) ICOM Comm. Conserv., 2002.

[33] H.E. Silva, F.M.A. Henriques, Preventive conservation of historic buildings in temperate climates. The importance of a risk-based analysis on the decision-making process, Energy Build. 107 (2015) 26-36, https://doi.org/10.1016/j. enbuild.2015.07.067.

[34] E. Schito, D. Testi, Integrated maps of risk assessment and minimization of multiple risks for artworks in museum environments based on microclimate control, Build. Environ. 123 (2017) 585-600, https://doi.org/10.1016/j.buildenv.2017.07. 039 .

[35] M. Strlic, C.M. Grossi, C. Dillon, N. Bell, K. Fouseki, P. Brimblecombe, E. Menart, K. Ntanos, W. Lindsay, D. Thickett, F. France, G. De Bruin, Damage function for historic paper, Part I: fitness for use, Herit. Sci. 3 (2015) 1-12, https: //doi.org/10.1186/s40494-015-0062-1.

[36] K. Sedlbauer, Prediction of mould fungus formation on the surface of and inside building components, Fraunhofer Institute Build. Phys., 2001.

[37] European Committee for Standardization (CEN), EN 15898, Conservation of cultural property, Main general terms and definitions, 2011. 28.

[38] E. Schito, D. Testi, W. Grassi, A proposal for new microclimate indexes for the evaluation of indoor air quality in museums, Buildings 6 (2016) 41-56, https:// doi.org/10.3390/buildings6040041.

[39] J. De Sousa Gomes, Estudo do ambiente interior na Biblioteca Joanina, MSc Thesis Mech. Eng. Degree Univ. Coimbra Port. (2017).

[40] P. Mendes, C. Fiolhais, Biblioteca Joanina, 2013. https://www.uc.pt/imprensa uc/catalogo/outros/biblioteca joanina.

[41] L. Dias Pereira, A. Rodrigues Gaspar, J.J. Costa, Assessment of the indoor environmental conditions of a baroque library in Portugal, Energy Procedia. 177 (2017) 257-267, https://doi.org/10.1016/j.egypro.2017.09.385.

[42] A.R. Gaspar, D.A. Quintela, A.R. Figueiredo, Aspectos do comportamento higrotérmico de um edifício de elevada inércia térmica. Caso de uma biblioteca do século XVIII, in: M. Vázquez Vázquez, J.C. Morán González (Eds.), Energías Limpias En Prog. Libr. Actas Del VII Congr. Ibérico Energía Sol., Vigo, Spain, 1994, pp. 657-662.

[43] I.N. Catarino, Análise das Condições Higrotérmicas na Biblioteca Joanina, Coimbra, 2010.

[44] Onset, HOBO UX 100-003, (2018).

[45] E. Schito, L. Dias Pereira, D. Testi, M. Gameiro da Silva, Data of temperature and relative humidity in a historic library in Portugal, Data Br. (2018), (submitted).

[46] R.J. Moffat, Describing the uncertainties in experimental results, Exp. Therm. Fluid Sci. 1 (1988) 3-17, https://doi.org/10.1016/0894-1777(88)90043-X. 